\title{
Development of an Improved Domestic Grinding Machine
}

\author{
B. Kareem* and R.A. Akinode \\ ${ }^{\dagger}$ Department of Mechanical Engineering, Federal University of Technology Akure, P.M.B 704 Akure, Nigeria.
}

Received 12 Feb 2018, Accepted 15 April 2018, Available online 19 April 2018, Vol.8, No.2 (March/April 2018)

\begin{abstract}
The major thrust of this paper is the development of an improved domestic grinding machine operated and mostly used in kitchen for the grinding of vegetables, spices and grains of any form. The challenges facing the separation of grinded ferrous metallic particles from the products grinded have been solved through the introduction of magnetic substance at the exit compartment called extractor. The testing of the machine was extensively carried out on dried (cayenne) pepper with 97\% efficiency of the operation. The construction of the work is simple and it employs the maximum utilization of locally sourced materials, which are readily available hence, a reduction in its total cost.
\end{abstract}

Keywords: Grinding Machine, Kitchen, Cayenne, Ferrous Metallic Particles, Extractor.

\section{Introduction}

For several decades, men were faced with challenges of particles being grinded alongside with vegetables, spices or grains with the available grinders, however, the grinded products were unknowingly consumes by the consumers and thereby cause series of illness in the human system Globally, moving away from traditional foods to more refined Western diets has been linked to increases in the prevalence of chronic non-communicable diseases (Suleyman, 2014) of which over the years, the means to overcome this challenge has been searching for.

Most developing countries like Nigeria experience high mortality rate and this is exacerbated by poor health delivery and inadequate monitoring of foodstuffs which results in high intake of unwholesome food. High level of trace metals in food is a potential source of disease when consumed by humans and constant monitoring of foodstuff for trace metal contamination is crucial for the health of the citizenry due to the various diseases they induce. Unhygienic grinding of foodstuff with old and worn out grinding machines is the usual practice in Nigerian markets and the operators do not appreciate the health risks involved in their operations (Jude and Prosper, 2016).

Heavy metals disrupt basic metabolic functions in two ways: on one hand, they disrupt the functioning of vital organs and glands such as the heart, brain, kidney, bone or liver, on the other hand, they move nutrients that are essential minerals and prevent them from fulfilling their biological functions. For example, aluminum as a chelator has the ability to capture and

*Corresponding author's ORCID ID: 0000-0002-8290-2168 DOI: https://doi.org/10.14741/ijcet/v.8.2.31 prevent the uptake of essential elements such as calcium, zinc and copper, and disrupt the proper use of many of them (Dabonne et al, 2010). This metal is heavily involved in the onset of Alzheimer's disease. It is responsible for the alteration of neurons (Miu and Beng, 2006; Bharathi et al., 2008). Depending on the heavy metal in question, toxicity can occur at levels just above naturally occurring background levels, meaning that consumption of foods with a high heavy metal concentration can cause acute or chronic poisoning (Llobet et al, 2003). Poisoning can result in damaged or reduced mental and central nervous function, as well as damage to blood composition, lungs, kidneys, liver, and other vital organs. Long-term exposure to heavy metals may result in slowly progressing physical, muscular, and neurological degenerative conditions as well as cancer (Llobet et al, 2003). A domestic grinding machine is basically (within the scope of this project) a manually operated domestic grinder/miller (i.e. hand driven machine) that is used to grind various product like vegetables, spices and some grains of any form without the usual metallic particles being eating by human being.

Metal pieces and abrasion from processing machines or equipment like cutting machines, mills, pneumatic transport etc. can contaminate the plant materials. To ensure that fine metal particles are kept to a minimum it is usual to install magnets before and after any particle size reducing equipment (Olsen, 1998; FDA., 2005). Magnets can reduce magnetic metal pieces. Their effect is limited only for ferrous material such as iron. Non-ferrous or stainless steel metals cannot be removed by usual magnets. Magnetic particles embedded in the plant materials can only be removed partly depending on the strength of the 
magnet and the weight of the plant material. For example heavy spices with a dusting of low magnetic contamination might not stick to the magnet. Similar to sieves, magnets are often a significant step in a spice processing operation and thus their control is important (Olsen, 1998; FDA., 2005).

Today as man's improves in different technological activities, the usual pepper milling machine has been converted to series of products grinder for example like the grinding of melon (both dried \& wet), grains (like corn meant for pap, beans for cake, rice for massa etc.) and also tuber in it dried from (i.e. elubo) etc. (Africanfoods, 2017). A domestic grinding machine basically consists of a lever, shaft, grinding disc, cone and hopper. It also has the operator's seat, particles (magnet) extractor and Adjuster. The lever is the source of driving force in the mills; the bed is the component through which the whole body including the operator seat is mounted, all the transmission is through the shaft from the lever to the grinding disc. Generally, domestic grinding machines are of different types, sizes, capacities and horse power, depending on the design and the purposes they are to fulfill. But this project focuses on the type that can be used in the kitchen for the grinding of small quantity of product. The mass is less than $5 \mathrm{~kg}$.

\section{Theoretical Analysis}

The domestic grinding machine has major components such as; Feeding Chamber that consist of hopper and feeder which is the point at which the products is loaded into the hopper where coiled spring/feeder will channel the compressed products into the grinding chamber. Grinding chamber consist of grinding discs, adjustable screw and cone which is the point at which the feeded products will be grinded/blend through the two grinding discs rubbing together during the operation. The transmission chamber that is consists of lever, shaft and control lever bearing which is the point at which the hand driver lever will transmit the motion through the shaft to the grinding discs where the work will be done. Also the adjustable lever at the opposite side of the driver lever is used to increase the effect of the grinding discs in the chamber. The extractor chamber that consist of compacted magnetic substance in an enclosed sheet ferrous metal rectangular plate mounted at the exit point of the chamber with an angle approximately $45^{\circ}$ which will allow free flow of grinded product but trap the ferrous metallic substance.

The hopper is mounted in such a way that the products have free flow into the grinding chamber in a control manner. As the lever rotate, it pushes the product into the grinding section and as the two discs rubbing each other the product is grinded into powder. As the powder trying to drop the ferrous metallic particles were trapped at the exit point of the machine through the help of the extractor and the grinded powder product without ferrous metallic particles dropped in a container.

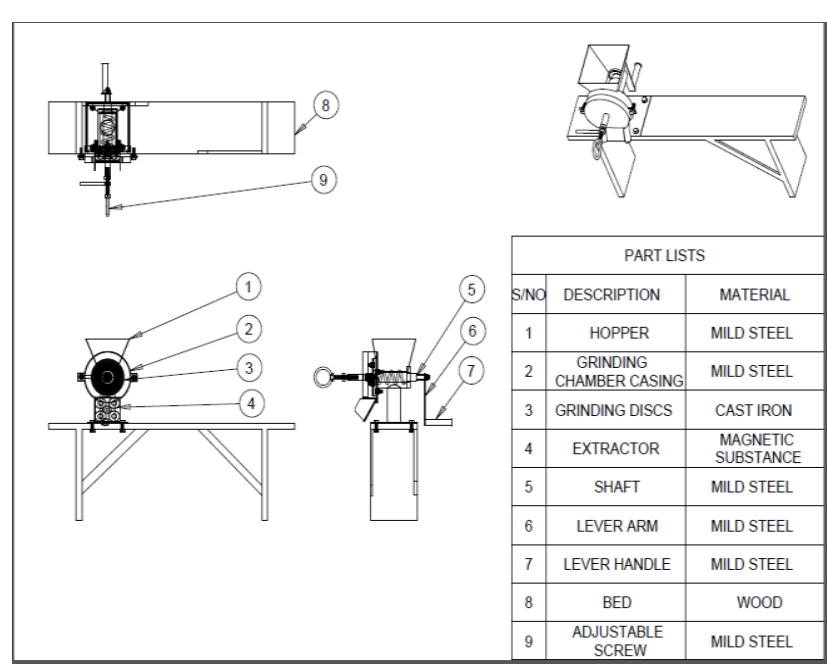

Fig.1 Domestic grinding machine

\subsection{Design analysis}

Mass of the hopper $=$ Density of mild steel $\mathrm{X}$ volume of hopper.

$M=\rho \times V$

Volume of hopper $=$ External volume of the hopper Internal volume of the hopper

Where:

Volume of the hopper $=\frac{\mathrm{h}}{3}\left[\left(\mathrm{ab}+\mathrm{cd}+\frac{(\mathrm{ad}+\mathrm{bc})}{2}\right]\right.$

For equivalent length of a composite shaft

Density of steel $(\rho)=7850 \mathrm{~kg} / \mathrm{m}^{3}$

$L=\frac{G L_{1} d^{4}}{G_{1} d_{1}^{4}}+\frac{G L_{2} d^{4}}{G_{2} d_{2}^{4}}+\frac{G L_{3} d^{4}}{G_{3} d_{3}^{4}} \quad$ (equivalent length)

Where:

$\mathrm{G}=$ Modulus of rigidity of the equivalent shaft $\left(\mathrm{N} / \mathrm{m}^{2}\right)$

$\mathrm{G}_{1}=$ Modulus of rigidity of shaft $(1)\left(\mathrm{N} / \mathrm{m}^{2}\right)$

$\mathrm{G}_{2}=$ Modulus of rigidity of shaft $(2)\left(\mathrm{N} / \mathrm{m}^{2}\right)$

$\mathrm{G}_{3}=$ Modulus of rigidity of shaft $(3)\left(\mathrm{N} / \mathrm{m}^{2}\right)$

$L, L_{1}, L_{2}, L_{3}$, are the lengths of the equivalent shaft, shaft

(1), shaft (2), shaft (3), (m), respectively;

\section{$\mathrm{T}=$ Driving Torque $=$ Resisting Torque $(\mathrm{N} / \mathrm{m})$}

Where $d, d 1, d 2$ and $d 3$ are the diameters of the equivalent shaft, (1), (2) and (3) respectively.

Determination of Composite Shaft Diameter

$d=\left[\sum_{i=1}^{n}\left(\frac{m_{i}}{m}\right)\left(\frac{1}{d_{i}}\right)^{6}\right]^{-\frac{1}{6}}$

Mass of each shaft: $m_{i}=m_{1}+m_{2}+m_{3}$

Diameter of each shaft: $\mathrm{d}_{\mathrm{i}}=\mathrm{d}_{1}+\mathrm{d}_{2}+\mathrm{d}_{3}$ (Dauda, and Okechukwu, 2013). 
Capacity of the Feeding Chamber

$\mathrm{V}=\pi \mathrm{r}^{2} \mathrm{~h}$

Where:

$\mathrm{V}=$ volume $\left(\mathrm{cm}^{3}\right)$

$\mathrm{r}=$ radius $(\mathrm{m})$

$\mathrm{h}=$ height $(\mathrm{h})$

Angle of twist for the composite sheet

$\theta=\Theta_{1}+\theta_{2}+\theta_{3}=\frac{\mathrm{TL}}{\mathrm{GJ}}=\frac{\mathrm{TL}_{1}}{\mathrm{GJ}_{\mathrm{i}}}=\frac{\mathrm{TL}_{2}}{\mathrm{GJ}_{2}}=\frac{\mathrm{TL}_{3}}{\mathrm{GJ}_{3}}$

$\theta=\frac{T L}{G J}$

Torque

$\mathrm{T}=\frac{\mathrm{G} \Theta \mathrm{J}}{\mathrm{L}}(\mathrm{Nm})$

Power

$\mathrm{P}=\frac{2 \pi N T}{60}(\mathrm{w})$

Volume of the Composite Shaft

$\mathrm{V}=\frac{\pi \mathrm{d}_{1}^{2} \mathrm{~L}_{1}}{4}+\frac{\pi \mathrm{d}_{2}^{2} \mathrm{~L}_{2}}{4}+\frac{\pi \mathrm{d}_{3}^{2} \mathrm{~L}_{3}}{4}$

Calculating the Magnetic Force (Force between Magnets)

$\mathrm{F}=\frac{\mathrm{B}^{2} \mathrm{~A}}{2 \mu_{0}}$

Where: $\mathrm{F}=$ force in Newton

$A=$ cross sectional area of the pole in $\mathrm{m}^{2}$

$\mathrm{B}=$ magnetic induction exerted by the magnet.

\subsection{Material selection}

The particular conditions under which the various parts of the Domestic grinding machine are subjected to, makes it necessary to select adequate materials for the fabrication based on functionality, durability, ability to withstand vibration and the cost of such materials. In the choice of material, their physical properties and behaviour are considered such that when subjected to the machine running condition should be able to withstand the service condition. In this design, the strength of the materials, serviceability of parts and availability were put into consideration. This led to the selection of mild steel rod for the shaft, mild steel plate of gauges 24 for the body including the hopper, the grinding chamber and the feeding chamber. Cast iron was selected for the grinding discs. Magnetic substances were selected for the extractor. Also painting of the machine was carried out for aesthetic aspect and to prevent rusting of parts.

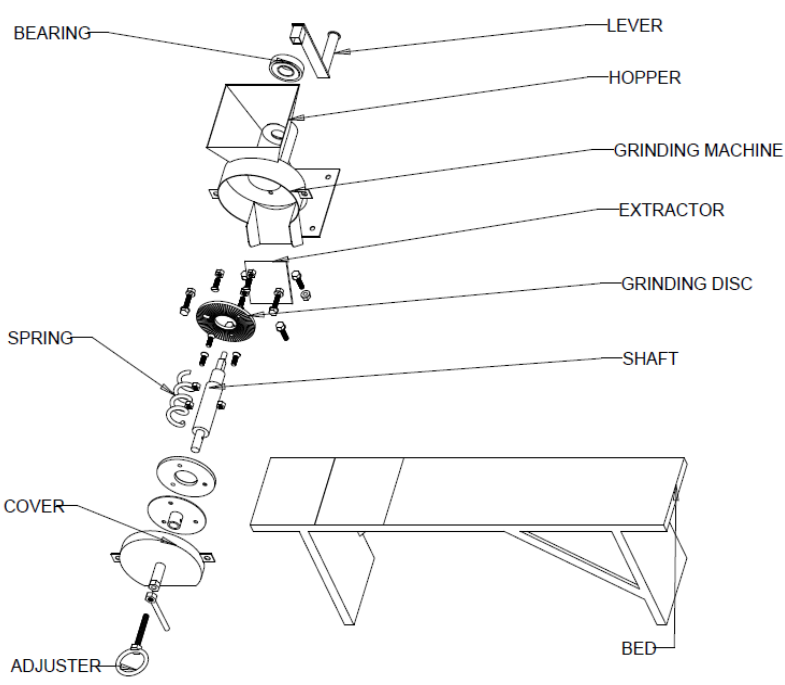

Fig. 2a Exploded view of the grinding machine

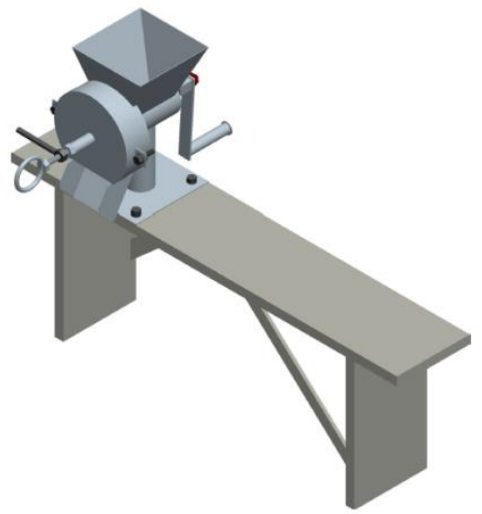

Fig. 2b Grinding machine assembly

\section{Test and Result Analyses}

After the construction, the domestic grinding machine was tested in the laboratory and the following results were obtained. The result of the test performed on the dried (cayenne) pepper is carried out in batches of A, B and $\mathrm{C}$ in order to ensure the correct statistics of the specimen measured. The results of the test performed on powder Pepper in each of the batch specimens using DIGITAL WEIGHING BALANCE model at the Mechanical Engineering Workshop Federal University of Technology Akure, Ondo State are presented in tables 1 - 3. The weight of the pepper loss in operations of batch ' $A$ ' and batch ' $\mathrm{B}$ ' is averagely $1.6 \%$ in approximation. Therefore the percentage loss in the total weight of the pepper is negligible compare to the health risks (Tables 1 and 2). The weight of the pepper loss in operations of batch ' $\mathrm{C}$ ' is averagely $1.3 \%$ in approximation. Therefore the percentage loss in the total weight of the pepper is negligible compare to the health risks (Table 3 ). On the specimen of $72.0012 \mathrm{~g}$ grinded, the weight of particles that escape the trapping chamber is $0.0011 \mathrm{~g}$ while $0.0362 \mathrm{~g}$ is the total particles generated as shown in the stated tables (1-3), 
from which efficiency of the machine is estimated as 97 $\%$ as illustrated below.

Efficiency $=\frac{\text { Total weight of particles }- \text { weight of escape }}{\text { Total weight of particles }}$

$=\frac{0.0362-0.0011}{0.0362} \times 100 \%$

$=96.9 \%$

$=97 \%$

Table 1 Particle weight and weight loss (Batch A)

\begin{tabular}{|l|l|l|l|l|l|l|l|}
\hline Operation & $\begin{array}{l}\text { Weight } \\
\text { before } \\
\text { grinding } \\
(\mathrm{g})\end{array}$ & $\begin{array}{l}\text { Weight } \\
\text { after } \\
\text { grinding } \\
(\mathrm{g})\end{array}$ & $\begin{array}{l}\text { Weight } \\
\text { of nylon } \\
(\mathrm{g})\end{array}$ & $\begin{array}{l}\text { Weight of } \\
\text { pepper } \\
\text { plus } \\
\text { particle } \\
(\mathrm{g})\end{array}$ & $\begin{array}{l}\text { Weight of } \\
\text { particle } \\
\text { after } \\
\text { separation } \\
(\mathrm{g})\end{array}$ & $\begin{array}{l}\text { Weight of } \\
\text { pepper } \\
\text { after } \\
\text { separation } \\
(\mathrm{g})\end{array}$ & $\begin{array}{l}\text { Weight of } \\
\text { wastage } \\
\text { pepper }(\mathrm{g})\end{array}$ \\
\hline $1^{\text {tu }}$ & 72.0012 & 70.4914 & 0.5133 & 1.0432 & 0.0351 & 1.0081 & 1.5098 \\
\hline $2^{\text {zid }}$ & 70.4914 & 69.0213 & 0.5133 & 1.5314 & 0.0471 & 1.4843 & 1.4701 \\
\hline $3^{\text {ri }}$ & 69.0213 & 67.4611 & 0.5133 & 1.0013 & 0.0302 & 0.9711 & 1.5602 \\
\hline Total & & & & & 0.1124 & & 4.5401 \\
\hline
\end{tabular}

Table 2 Particle weight and weight loss (Batch B)

\begin{tabular}{|l|l|l|l|l|l|l|l|}
\hline Operation & $\begin{array}{l}\text { Weight } \\
\text { before } \\
\text { grinding } \\
\text { (g) }\end{array}$ & $\begin{array}{l}\text { Weight } \\
\text { after } \\
\text { grinding } \\
(\mathrm{g})\end{array}$ & $\begin{array}{l}\text { Weight of } \\
\text { nylon (g) }\end{array}$ & $\begin{array}{l}\text { Weight of } \\
\text { pepper } \\
\text { plus } \\
\text { particle } \\
(\mathrm{g})\end{array}$ & $\begin{array}{l}\text { Weight of } \\
\text { particle after } \\
\text { separation(g) }\end{array}$ & $\begin{array}{l}\text { Weight of } \\
\text { pepper } \\
\text { after } \\
\text { separation } \\
\text { (g) }\end{array}$ & $\begin{array}{l}\text { Weight of } \\
\text { wastage } \\
\text { pepper (g) }\end{array}$ \\
\hline $1^{\text {st }}$ & 74,0110 & 72.5112 & 0.5133 & 1.4921 & 0.0318 & 1.4603 & 1.4998 \\
\hline $2^{\text {at }}$ & 72.5112 & 70.4912 & 0.5133 & 1.0012 & 0.0174 & 0.9838 & 2.0200 \\
\hline $3^{\text {nt }}$ & 70.4912 & 69.0101 & 0.5133 & 0.9216 & 0.0244 & 0.8972 & 1.4811 \\
\hline Total & & & & & 0.0736 & & 5.0001 \\
\hline
\end{tabular}

Table 3 Particle weight and weight loss (Batch C)

\begin{tabular}{|c|c|c|c|c|c|c|c|}
\hline Operation & $\begin{array}{l}\text { Weight } \\
\text { before } \\
\text { grinding } \\
\text { (g) }\end{array}$ & \begin{tabular}{|l|} 
Weight \\
after \\
grinding \\
(g) \\
\end{tabular} & $\begin{array}{l}\text { Weight of } \\
\text { nylon (g) }\end{array}$ & \begin{tabular}{|l|} 
Weight of \\
pepper \\
plus \\
particle \\
(g)
\end{tabular} & \begin{tabular}{|l|} 
Weight of \\
particle after \\
separation(g)
\end{tabular} & \begin{tabular}{|l|} 
Weight of \\
pepper \\
after \\
separation \\
(g)
\end{tabular} & \begin{tabular}{|l} 
Weight of \\
wastage \\
pepper (g)
\end{tabular} \\
\hline $1^{1 *}$ & 72.0013 & 71.0193 & 0.5133 & \begin{tabular}{|l|l|}
0.8314 \\
\end{tabular} & 0.0321 & 0.7993 & 0.9820 \\
\hline $2^{\text {nat }}$ & 71.0193 & \begin{tabular}{|l|}
70.0341 \\
\end{tabular} & 0.5133 & \begin{tabular}{|l|l|}
1.0172 \\
\end{tabular} & 0.0109 & 1.0063 & 0.9852 \\
\hline $3^{\text {nd }}$ & 70.0341 & \begin{tabular}{|l}
68.4712 \\
\end{tabular} & 0.5133 & \begin{tabular}{|l|}
1.0111 \\
\end{tabular} & \begin{tabular}{|l|}
0.0391 \\
\end{tabular} & 0.9720 & 1.5629 \\
\hline Total & & & & & 0.0821 & & 3.5301 \\
\hline
\end{tabular}

\section{Conclusions}

The development of an improved domestic grinding Machine was successfully carried out by this work with an efficiency of $96.9 \%$ attained. The machine was tested and found capable of removing ferrous metallic particles from the grinded product. Due to the low cost of fabrication the machine can be adopted by small scale producers. This was also done in line with the government policy on technological development and economic diversification in Nigeria.
The domestic pepper grinding machine was designed, fabricated and tested with (cayenne) dried pepper at approximately zero moisture content. From the performance results the following conclusions can be drawn:

1) The grinder has the ability to remove ferrous metallic particle from grinded powder pepper.

2) A dried grinded pepper of approximately zero moisture content of variable pepper dimension was achievable.

3) The maintenance of the machine is easier than the existing ones in terms of the parts, the size and weight

4) Perfectly operational efficiency is achieved in terms of ferrous metallic particles removal.

Summarily, the domestic grinding machine is cheaper to buy than the existing ones made locally or from abroad.

\section{References}

S. Dabonne, B.P.K. Koffi, E.J.P. Kouadio, A.G. Koffi, E.A. Due and L.P. Kouame, (2010). Traditional Utensils: Potential Sources of Poisoning by Heavy Metals. British Journal of Pharmacology and Toxicology 1(2): 90-92.

M. Dauda. and C. Okechukwu, (2013): Development of a diameter model for the determination of the equivalent lengths of composite shafts. The International Journal of Engineering and Science (IJES), Vol.:2, PP.46-51.

FDA. (2005): Food - Adulteration involving hard or sharp foreign objects. FDA/ORA compliance policy guide, chapter 5 , sub - chapter 555, section 555.425. Department of health and human services, public health service, food and drug administration, Washington DC.

R.S. Khurmi. and J.K. Gupta, (2012): Machine design, Eurasia publishing house (P) Ltd., New Delhi.

J.M. Llobet, G. Falco, G. Casas, A. Teixido and JL Domingo, (2003).Concentrations of arsenic, cadmium, mercury and lead in common foods and estimated daily intake by children, adolescents, adults and seniors of Catalonia, Spain. J. Agric. Food Chem; 51: 838 - 842.

A.C. Miu, and O. Beng, (2006). Aluminum and Alzheimer's disease: A new look. J. Alzheimers Disease., 10(2-3):179201.

A.R. Olsen, (1998): Regulatory action criteria for filth and other extraneous materials. Review of hard or sharp foreign objects as physical hazards in food. Regulatory Toxicology and Pharmacology 28: 181 - 189.

R.K. Rajput, (2012): Strength of materials: $S$ Chand and company Ltd: New Delhi.

M.D. Suleyman, (2014): African indigenous food crops: their roles in combating chronic diseases in Ghana. Department of Social Justice, University of Toronto.

Africanfoods, (2017) www.africanfoods.co.uk/elubo.html. Accessed June, 2017. 